\title{
Susceptibility to malaria during the Prevention of Re- establishment phase in Sri Lanka
}

Hamsananthy Jeevatharan ( $\sim$ hamsa.jeeva@gmail.com )

Ministry of Health,Sri Lanka https://orcid.org/0000-0001-5030-5353

Wickremasinghe AR

Faculty of Medicine ,University of Kelaniya

\section{Research}

Keywords: Malaria Parasite, Social vulnerability, Susceptibility, Prevention of Re-establishment of malaria, Sri Lanka

Posted Date: November 10th, 2020

DOI: https://doi.org/10.21203/rs.3.rs-53968/v2

License: (우 (7) This work is licensed under a Creative Commons Attribution 4.0 International License. Read Full License 


\section{Abstract}

\section{Background}

Susceptibility to malaria is the predisposition of populations to be infectedby malaria parasites. It is influenced by the age-sex composition, parasitaemia, immunity, pregnancy status, type of residency, socio economic status, migration history of the population; broadly biological and generic factors. As imported cases are still being reported and one introduced malaria case was reported in 2018, prevention of reestablishment of malaria is a challenge for Sri Lanka.Addressing susceptibility to malaria is crucial for planning and implementing appropriate interventions to sustain malaria-free status of the country. The aim of this study was to assess susceptibility to malaria during the prevention of re-establishment phase in Sri Lanka.

\section{Methods}

A national survey was conducted among 3,454 households. A multistage cluster sampling technique was used to select the households. Susceptibility was assessed based on a conceptual framework adapted from Kienberger and Hagenlocher [20], using an interviewer-administered questionnaire administered to heads of households. Basic socio-demographic information, travel history, history of fever and past malaria infections in the preceding three years were collected; in addition, subjects were tested for presence of malaria parasites. Data were analysed using SPSS version 20 package.

\section{Results}

The proportion of population who had been overseas within the last 3 years in the urban sector $(4.5 \%, n=99)$ was significantly higher than that of the rural $(2.8 \%, n=288)$ and estate sectors $(0.2 \%, n=2)\left(\chi_{4}{ }^{2}=66.103\right.$; $p<0.001)$. The proportions reporting overseas travel declined significantly with the wealth index up to the $4^{\text {th }}$ quintile with a slight rise in the $5^{\text {th }}$ quintile $\left(\chi_{8}{ }^{2}=60.985 ; P<0.001\right)$. There were 177 persons who had fever within the past 2 weeks of the survey. None of the surveyed population had malaria parasites on blood examination.

\section{Conclusions}

Urban and upper socioeconomic class population should be targeted for screening and awareness programmes on prevention of re-establishment of malaria. Travel overseas is the most important criterion to assess susceptibility in an island nation.

As susceptibility is a dynamic phenomenon, it should be assessed periodically. Combining it with resilience and receptivity, social vulnerability and risk of re-establishment of malaria could be assessed.

\section{Background}

The burden of malaria has decreased in many countries over the last decade due to accelerated prevention and control activities. In 2019, there were about 228 million cases of malaria and an estimated 405,000 
deaths due to malaria [1]. Over the last decade, 10 countries have been certified by the WHO as malaria-free: Morocco (2010), Turkmenistan (2010), Armenia (2011), Maldives (2015), Sri Lanka (2016), Kyrgyzstan (2016), Paraguay (2018), Uzbekistan (2018), Argentina (2018) and Algeria (2019) [1]. However, there has been no significant progress in reducing the global malaria burden during 2015-2017 [2]. The achievement of malaria elimination carries with it the risk of malaria re-establishment. The risk of re-establishment of malaria is a challenge for countries that have eliminated malaria until global eradication of malaria.

Sri Lanka was certified as malaria-free in September 2016 with no indigenous case of malaria being reported since November 2012. There was one introduced malaria case in December 2018. Less than 100 imported malaria cases have been reported annually from 2013 onwards, among both Sri Lankans traveling overseas and foreign nationals coming into the country, maintaining the susceptibility of the country to malaria in a receptive environment [3-5]. Thus, there is a potential threat for the re-establishment of malaria in Sri Lanka.

The understanding of malariogenic potential of a country is essential for implementation of cost-effective interventions to prevent re-establishment of malaria. The malariogenic potential is the degree of risk of malaria transmission which depends on receptivity, vulnerability and infectivity. Receptivity to malaria transmission is determined by the presence of competent vectors, a suitable climate and a susceptible population. Vulnerability refers to the rate of importation of parasites through the movement of infected individuals or, occasionally, infected Anopheline vectors. Infectivity, or vector susceptibility, depends on the compatibility between the Anopheline vector and the infecting strain of Plasmodium [6].

\section{Susceptibility to malaria during the prevention of re-establishment phase in Sri Lanka}

Susceptibility of the population is the predisposition of being negatively affected by an outbreak. It is determined by biological susceptibility factors such as age and sex, and generic susceptibility factors such as migration and socio economic status of the population [7].

Migration of people between Sri Lanka and malaria endemic countries is the most important susceptibility factor in the prevention of re-establishment of malaria phase. It is the main route of entry of malaria parasites into the country after elimination. The risk groups in whom imported malaria was reported include; asylumseekers, local fishermen who returned from Sierra Leone, army personnel returning after serving in UN peacekeeping missions in Haiti and South Sudan, irregular migrants from Myanmar, foreign skilled and unskilled labour working in several parts of the country, Sri Lankan nationals engaged in business in African countries and in India, tourists and foreign labour [8]. Figure 1 shows the reported malaria cases in 2018 by risk category [9].

Figure 1. Malaria cases reported in Sri Lanka in 2018 by risk category [9]

The importance of social factors that make some groups or individuals more susceptible to infection and more limited in their ability to respond to illness than others was highlighted in a study of social vulnerability assessment of vector-borne diseases [7]. In Sri Lanka, being an island nation, malaria is no more a 'disease of the poor' because of the influence of social class on migration. The number of travelers from malaria 
endemic countries has a direct impact on vulnerability to malaria in a receptive area. Children, pregnant women and immuno-compromised persons such as HIV/AIDS and tuberculosis patients are the more susceptible groups, in general [10].

Wessen states that "only in retrospect has it become fully clear that the failure of malaria eradication was in large part a failure at the social and organization levels" [11]. Several studies have shown that socio-cultural factors should have been taken into account at the initial stage of the programme and for the recommendation of programme design [12].

There are no published studies on susceptibility to malaria during the prevention of re-establishment phase in Sri Lanka. There are some studies which assessed the influence of certain social aspects on malaria control during the control phase $[13,14]$. This study assessed susceptibility to malaria during the prevention of reestablishment phase in Sri Lanka.

\section{Methods}

This cross sectional study covered the whole country.

\section{Study setting}

Sri Lanka is an island nation in the Indian Ocean, southeast of India, with a total land area of $65,610 \mathrm{~km}^{2}$. The population of Sri Lanka is approximately 21 million. Approximately $18 \%$ of the population is resident in urban areas [15]. Administratively, Sri Lanka is divided into 9 provinces, and the 9 provinces are further divided into 25 districts. The Medical Officer of Health $(\mathrm{MOH})$ is responsible for preventive health services in a defined area. The $\mathrm{MOH}$ area is further divided into Public Health Inspector (PHI) and Public Health Midwife (PHM) areas [3].

The study population consisted of members of all households in all districts of Sri Lanka. A household was defined as 'one or more persons living together and who have a common arrangement for provision of food living in a housing unit' [16]. Public places like homes for elders, orphanages, and religious homes were excluded.

\section{Conceptual setting: Susceptibility as adomain of the social vulnerability framework}

Social vulnerability is a developing concept on communication of natural hazards and disasters and is partially the result of social inequalities. Social factors influence susceptibility of various groups and their ability to respond to harm [17]. Social vulnerability is not only due to exposure to hazards alone, but also depends on the sensitivity and resilience of the system to prepare, cope and recover from such hazards [18]. Wisner al. define vulnerability as "the characteristics of a person or group in terms of their capacity to anticipate, cope with, resist and recover from the impact of a natural hazard" [19]. Methods for the Improvement of Vulnerability Assessment in Europe (MOVE) project have elaborated a framework in the context of natural hazards and climate change [7].

Figure 2 Conceptual framework for social vulnerability adapted from Kienberger, S., \& Hagenlocher, M. [20] 
Susceptibility domains were adapted from the conceptual framework for social vulnerability to vector borne diseases by Kienberger \& Hagenlocher (Figure 2) [20]. Kienberger and Hagenlocher define social vulnerability to malaria as the predisposition of the population to acquire malaria [20]. It is characterized by different interrelated domains, generic and biological susceptibility, and lack of resilience. The generic and biological susceptibility factors predispose a community to the malaria burden. The resilience factors determine the community's ability to anticipate, respond to, cope with, or recover from the malaria burden.

\section{Adapted framework for susceptibility to malaria during the prevention of reestablishment phase}

Based on the review of literature and extensive consultations with malaria experts, social vulnerability indicators of malaria during the prevention of re-establishment phase in Sri Lanka were identified under two main domains; susceptibility and resilience. The susceptibility domain, assessed in this study, is shown in Figure 3.

Figure 3: Adapted framework for susceptibility to malaria during the prevention of reestablishment phase from Kienberger and Hagenlocher [20]

Age, gender, pregnancy status, prevalence of parasitaemia, and history of malaria (immunity status) during the past 3 years were considered as biological susceptibility indicators. Migration, socio-economic status and residency of the population (urban/rural/estate) were considered as generic susceptibility indicators. Urban areas were defined as all areas administered by municipal and urban councils. 'Pradeshiya Sabhas' were included under the rural sector. Estate sector included the plantation areas [16]. Table 1 compares susceptibility indicators in the framework of Kienberger and Hegenlocher [20] and those used in this study with a justification for the selection of the indicators.

Table 1: Comparison of susceptibility indicators between framework of Kienberger and Hegenlocher [20] and the framework used in this study with justification 


\begin{tabular}{|c|c|c|c|}
\hline $\begin{array}{l}\text { usceptibility } \\
\text { ubdomains }\end{array}$ & $\begin{array}{l}\text { Kienberger } \\
\text { and } \\
\text { Hagenlocher, } \\
\text { during } \\
\text { control } \\
\text { phase [20] } \\
\text { (East Africa) }\end{array}$ & $\begin{array}{l}\text { Adapted for } \\
\text { PoR* phase } \\
2016 \\
\text { (Sri Lanka) }\end{array}$ & $\begin{array}{l}\text { Justification for the selection of } \\
\text { indicators }\end{array}$ \\
\hline $\begin{array}{l}\text { iological } \\
\text { usceptibility }\end{array}$ & $\begin{array}{l}\text { Number of } \\
\text { women of } \\
\text { childbearing } \\
\text { age } \\
\text { Number of } \\
\text { children } \\
\text { under 5 } \\
\text { Prevalence of } \\
\text { stunting in } \\
\text { children } \\
\text { under 5 } \\
\text { HIV } \\
\text { prevalence } \\
\text { among 15-49 } \\
\text { year olds } \\
\text { Altitude } \\
\text { (proxy for } \\
\text { immunity) }\end{array}$ & $\begin{array}{l}\text { - Age } \\
\text { - Gender } \\
\text { - Pregnancy } \\
\text { - Immunity (past } \\
\text { history of } \\
\text { malaria within } \\
\text { last } 3 \text { years) } \\
\text { - Parasitaemia }\end{array}$ & $\begin{array}{l}\text { Age }<5 \&>65 \text { and females are } \\
\text { susceptible groups for malaria. } \\
\text { Pregnant mothers and non- } \\
\text { immune persons are more prone } \\
\text { to get malaria. } \\
\text { Parasitaemia among the } \\
\text { population may lead to local } \\
\text { transmission. Due to the presence } \\
\text { of foreign labour in large } \\
\text { numbers, the return of refugees } \\
\text { from India re-settled in the } \\
\text { Northern Province and the } \\
\text { receptivity in the country, this } \\
\text { indicator was included. }\end{array}$ \\
\hline
\end{tabular}




\begin{tabular}{|c|c|c|c|}
\hline $\begin{array}{l}\text { usceptibility } \\
\text { ubdomains }\end{array}$ & $\begin{array}{l}\text { Kienberger } \\
\text { and } \\
\text { Hagenlocher, } \\
\text { during } \\
\text { control } \\
\text { phase [20] } \\
\text { (East Africa) }\end{array}$ & $\begin{array}{l}\text { Adapted for } \\
\text { PoR* phase } \\
2016 \\
\text { (Sri Lanka) }\end{array}$ & $\begin{array}{l}\text { Justification for the selection of } \\
\text { indicators }\end{array}$ \\
\hline $\begin{array}{l}\text { usceptibility } \\
\text { usceptic }\end{array}$ & 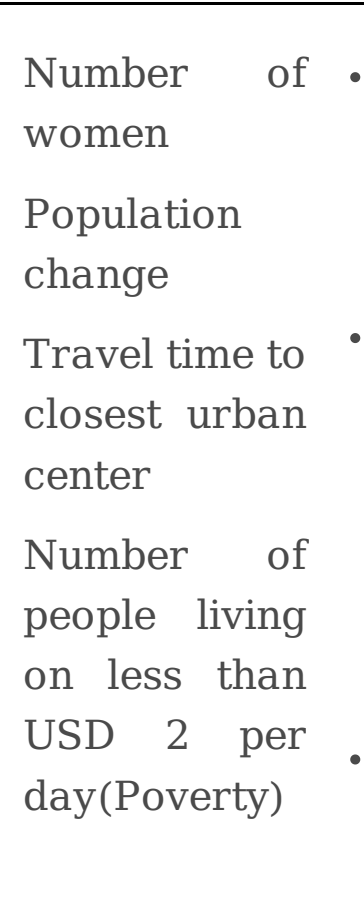 & $\begin{array}{l}\text { - Place of } \\
\text { residency(urban, } \\
\text { rural and estate } \\
\text { sectors) } \\
\text { - Migration }\end{array}$ & $\begin{array}{l}\text { Malaria was a disease of rural } \\
\text { populationswhere the receptivity } \\
\text { was higher. } \\
\text { History of travel to malaria } \\
\text { endemic countries is an important } \\
\text { factor for re-establishment of } \\
\text { malaria } \\
\text { There are differences in access to } \\
\text { health care, immunity and } \\
\text { migration patterns in different } \\
\text { socio-economic groups }\end{array}$ \\
\hline
\end{tabular}

PoR refers to prevention of re-establishment

\section{Development of the data collection tool}

Based on the conceptual framework, a household survey questionnaire was developed to assess susceptibility to malaria during the prevention of re-establishment phase. The following details were collected: identification of households including socio demographic characteristics of household members, and household characteristics to assess socio-economic status (SES). The assessment of socio economic status (SES) was based on the Demographic Health Survey (DHS) format used worldwide [22]. Wealth index was used to classify the socio-economic status of participants. The source of water, toilet facilities, type of fuel used, material used for the floor of the house, mode of transport, access to mass media, electricity in the household, possession of some household items, and ownership of agricultural land and farm animals were included in the questionnaire. The migration history of household members within the last 3 years and history of fever prior to two weeks of survey was included.

\section{Validation of tool}


Questionnaires along with the adapted conceptual framework were distributed among experts to assess judgmental validity (face and content) of the questionnaire. Face and content validities were assessed by malaria experts. The questionnaires were translated using standard methods and pre-tested in the field; necessary changes were made accordingly.

\section{Sample size and sampling}

For sample size calculation to assess susceptibility to malaria, there are no guidelines or literature that could be used in the prevention of re-establishment phase. Hence, we considered the number of Sri Lankans traveling overseas as the most important variable to consider in sample size calculation. In 2014, 1,311,258 Sri Lankans departed from the Bandaranaike International Airport which was about $6 \%$ of the estimated population [23]. Therefore, to estimate the proportion of Sri Lankans traveling overseas in a year as $6 \%$, with a margin of error ranging from $4.5 \%-7.5 \%$ for a $95 \%$ confidence interval, assuming a design effect of 3.2 for using cluster sampling (cluster size of 12), and a non-response rate of $10 \%$, a sample of 3424 households had to be surveyed [24]. Households were selected equally from among the 25 districts proportionate to population in urban, rural and estate sectors. Therefore, from each district 137 households had to be surveyed from 11.4 clusters per district. Hence, twelve clusters of 12 households from each cluster were randomly selected from each district ( 25 districts $\times 12$ PHM clusters $\times 12$ households) to give a total sample size of 3600 households.

A stratified multistage cluster sampling method was used with the primary sampling unit being $\mathrm{MOH}$ areas. 6$8 \mathrm{MOH}$ areas were randomly selected from each district. 12 Public Health Midwife (PHM) area clusters were randomly selected from the selected $\mathrm{MOH}$ areas (on average $2 \mathrm{PHM}$ clusters per $\mathrm{MOH}$ area). From each $\mathrm{PHM}$ area cluster, the starting point of the household survey was randomly selected by dropping a headed pin on the PHM area map and the house closest to the pointed edge was selected. After the first house was identified, every tenth house to the left of the selected house was chosen until 12 households for that PHM area were surveyed.

\section{Data collection}

The validated tool was used in the household survey in all districts of the country. The data collectors were trained on sampling technique and the importance of sampling during the training sessions; in the field they were supervised by malaria officers or the principal investigator. The manual for interviewers and Global Positioning System (GPS) data collection were prepared based on the guidelines for conducting Malaria Indicator Surveys as given by the Roll Back Malaria Initiative and given to all data collectors for easy reference. Fieldwork was carried out from July 2016 to March 2017.

The PHM of the area informed the heads of selected households about the survey and the date of interview. On the assigned date, data collectors visited the households and interviewed the head of the household. If the head of the household could not be interviewed (e.g.: household closed), the next closest household was selected. If the head of the household had responded and was not available at the time of survey, the contact number was obtained; the household head was approached a second time, after confirmation of his/her 
presence, mainly during weekends. If the second attempt failed, the house was visited for a third time; if the head of the household could not be contacted a third time, it was considered a non-responder.

Screening for malaria was done according to the standard operating procedure for parasitological screening for malaria of the Anti Malaria Campaign (AMC), Sri Lanka on the same day the house was visited. Both microscopy and RDTs were used for screening. RDTs were used in areas that did not have microscopy facilities. Microscopy was done by a trained Public Health Laboratory Technologist (PHLT) from each region. Data collection was supervised by regional malaria officers, medical officers attached to Anti Malaria Campaign/Headquarters and the principal investigator.

\section{Data Analysis}

Data analysis was done using IBM SPSS statistics version 20 software package. Descriptive analyses were used to describe socio-demographic characteristics. Socio-economic status of the population was assessed by the wealth index using exploratory factor analysis. Principal components analysis (PCA) was used to generate a weighted score based on household assets. The wealth index for a household is the linear combination defined as the principal component variable across households or individuals with a mean of zero and a variance of one, corresponding to the 'Eigenvalue' of the correlation matrix. The estimated wealth index was based on a population of 13,365 resident in 3,454 households located in all districts in Sri Lanka.

The variables selected for derivation of the wealth index were based on the methodology used by the Department of Census and Statistics in their routine surveys (DHS) [15] and in the guidelines to conduct a Malaria Indicator Survey[25].

Descriptive analysis was used to describe variables included in ascertaining biological susceptibility. The association between wealth index, sector of residency and history of migration was analyzed using the chisquare test.

\section{Results}

3454 out of the selected 3600 households (response rate of $95.9 \%$ ) responded within two consecutive visits. Figure 4 shows the geographic distribution of the surveyed households.

Figure 4: Geographic distribution of surveyed households

\section{Characteristics of the population of the household survey}

The mean age of the heads of the household was 51 years $(S D=13.9)$, the age ranging from 19 to 92 years. The majority of the heads of households were males $(n=2758 ; 79.8 \%)$; most heads of households were 41-60 year of age $(n=1317,38.1 \%)$. The age-sex distribution of household members is shown in table 2 . The agesex distribution of the surveyed population was similar to the national population estimates of 2016 (sample $<5$ years- $8.7 \%$ vs $8.6 \%$ national estimate; sample $>65$ years $-7.7 \%$ vs $7.9 \%$ national estimate) [26]. 
Table 2: Distribution of heads of households and household members by age and sex

\begin{tabular}{|c|c|c|c|}
\hline Age Group & $\begin{array}{l}\text { Male No. } \\
(\%, 95 \% \text { CI })\end{array}$ & $\begin{array}{l}\text { Female No. } \\
(\%, 95 \% \text { CI })\end{array}$ & $\begin{array}{l}\text { Total No. } \\
(\%, 95 \% \text { CI })\end{array}$ \\
\hline \multicolumn{4}{|l|}{ Heads of the Households } \\
\hline$<20$ & $\begin{array}{r}6 \\
(0.2,0.1-0.4)\end{array}$ & $\begin{array}{r}0 \\
(0.0)\end{array}$ & $\begin{array}{r}6 \\
(0.2,0.13-0.23)\end{array}$ \\
\hline $21-40$ & $\begin{array}{r}759 \\
(22.0,20.6-23.4)\end{array}$ & $\begin{array}{r}135 \\
(3.9,3.3-4.6)\end{array}$ & $\begin{array}{r}894 \\
(25.9,24.4-27.4)\end{array}$ \\
\hline $41-60$ & $\begin{array}{r}1317 \\
(38.1,36.5-39.8)\end{array}$ & $\begin{array}{r}317 \\
(9.2,8.2-10.2)\end{array}$ & $\begin{array}{r}1634 \\
(47.3,45.6-49.0)\end{array}$ \\
\hline$>60$ & $\begin{array}{r}676 \\
(19.6,18.3-20.9) \\
\end{array}$ & $\begin{array}{r}244 \\
(7.1,6.2-8.0) \\
\end{array}$ & $\begin{array}{r}920 \\
(26.6,25.2-28.1)\end{array}$ \\
\hline Total & $\begin{array}{r}2758 \\
(79.8,78.5-81.2) \\
\end{array}$ & $\begin{array}{r}696 \\
(20.2,18.8-21.5) \\
\end{array}$ & $\begin{array}{l}3454 \\
(100)\end{array}$ \\
\hline \multicolumn{4}{|l|}{ Household Members } \\
\hline$<5$ & $\begin{array}{c}627 \\
(4.7,4.3-5.1)\end{array}$ & $\begin{array}{r}536 \\
(4.0,3.7-4.4)\end{array}$ & $\begin{array}{r}1163 \\
(8.7,8.2-9.2)\end{array}$ \\
\hline $6-20$ & $\begin{array}{r}1556 \\
(11.6,11.1-12.2)\end{array}$ & $\begin{array}{r}1455 \\
(10.9,10.4-11.4)\end{array}$ & $\begin{array}{r}3011 \\
(22.5,21.8-23.3,)\end{array}$ \\
\hline $21-35$ & $\begin{array}{r}1529 \\
(11.4,10.9-12.0)\end{array}$ & $\begin{array}{r}1684 \\
(12.6,12.0-13.2)\end{array}$ & $\begin{array}{r}3213 \\
(24.0,23.3-24.8)\end{array}$ \\
\hline $36-50$ & $\begin{array}{r}1311 \\
(9.8,9.3-10.3)\end{array}$ & $\begin{array}{r}1389 \\
(10.4,9.9-10.9)\end{array}$ & $\begin{array}{r}2700 \\
(20.2,19.5-20.9)\end{array}$ \\
\hline $51-65$ & $\begin{array}{r}1098 \\
(8.2,7.8-8.7)\end{array}$ & $\begin{array}{r}1157 \\
(8.7,8.2-9.2)\end{array}$ & $\begin{array}{r}2255 \\
(16.9,16.2-17.5\end{array}$ \\
\hline$>65$ & $\begin{array}{r}519 \\
(3.9,3.6-4.2)\end{array}$ & $\begin{array}{r}504 \\
(3.8,3.5-4.1)\end{array}$ & $\begin{array}{r}1023 \\
(7.7,7.2-8.1)\end{array}$ \\
\hline Total & $\begin{array}{r}6,640 \\
(49.7,48.8-50.5) \\
\end{array}$ & $\begin{array}{r}6,725 \\
(50.3,49.5-51.2) \\
\end{array}$ & $\begin{array}{r}13,365 \\
(100) \\
\end{array}$ \\
\hline
\end{tabular}

The majority of heads of households was Sinhalese $(n=2,240,64.9 \%)$, married $(n=3032,87.8 \%)$ and employed $(n=2,995,86.8 \%)$ (Table 3). Seventy eight percent $(n=2693)$ of heads of households had more than primary education while $3.9 \%(n=133)$ had no schooling. The majority of families $(n=2,223,64.4 \%)$ had a monthly income between Sri Lanka Rupees (SLR) 10,000 - 50,000 (Table 3).

Table 3:Socio-demographic characteristics of Heads of households 


\begin{tabular}{|c|c|c|}
\hline Characteristic & & $\begin{array}{c}\text { Number }(\%, 95 \% \text { CI }) \\
(\mathrm{n}=3454)\end{array}$ \\
\hline \multirow[t]{4}{*}{ Ethnicity } & Sinhalese & $2240(64.9,63.2-66.5)$ \\
\hline & Tamil & $1001(28.9,27.5-30.5)$ \\
\hline & Muslim & $210(6.1,5.3-6.9)$ \\
\hline & Other & $3(0.1,0.02-0.25)$ \\
\hline \multirow[t]{4}{*}{ Marital status } & Married & $3032(87.8,86.6-88.7)$ \\
\hline & Unmarried & $62(1.8,1.4-2.3)$ \\
\hline & Divorced/Separated & $57(1.7,1.3-2.1)$ \\
\hline & Widowed & $303(8.8,7.9-9.8)$ \\
\hline \multirow[t]{6}{*}{ Educational level } & No schooling & $133(3.9,7.9-9.8)$ \\
\hline & Primary (Grade1-5) & $628(18.2,16.9-19.5)$ \\
\hline & Secondary(Grade 6-10) & $1019(29.5,28.0-31.1)$ \\
\hline & Completed $\mathrm{GCE}^{1} \mathrm{O} / \mathrm{L}^{2}$ or equivalent & $1060(30.7,29.3-32.3)$ \\
\hline & Completed GCE A $/ \mathrm{L}^{3}$ or equivalent & $532(15.4,14.2-16.6)$ \\
\hline & Degree and above & $82(2.4,1.9-2.9)$ \\
\hline \multirow[t]{3}{*}{ Occupation } & Employed & $2995(86.8,85.5-87.8)$ \\
\hline & Retired & $187(5.4,4.7-6.2)$ \\
\hline & Unemployed & $272(7.8,7.0-8.8)$ \\
\hline Monthly & $<$ Rs $10,000 /-$ & $945(27.4,25.9-28.9)$ \\
\hline \multirow[t]{5}{*}{ Family Income (SLR) } & Rs 10,001/- - Rs 30,000/- & $1505(43.6,41.9-45.3)$ \\
\hline & Rs 30,001/- - Rs 50,000/- & $718(20.8,19.4-22.2)$ \\
\hline & Rs 50,001/- - Rs 70,000/- & $212(6.1,5.4-7.0)$ \\
\hline & Rs 70,001/- - Rs 100,000/- & $64(1.9,1.4-2.4)$ \\
\hline & $>$ Rs $100,000 /-$ & $10(0.3,0.1-0.5)$ \\
\hline
\end{tabular}

$1_{\text {General Certificate of Education, }{ }^{2} \text { Ordinary Level, }{ }^{3} \text { Advanced level }}$

4 SLR refers to Sri Lankan rupees ( 1 USD $\approx$ SLR 150 at time of study)

The majority of households $(n=2,685,77.7 \%)$ and the household members $(n=10,231,76.5 \%)$, were from the rural sector (Table 4).

Table 4: Distribution of households by urban, rural and estate sectors 
Sector Number of households (\%,95\% Number of household members

CI) $(\%, 95 \% \mathrm{CI})$

\begin{tabular}{lrr}
\hline Urban & $573(16.6,15.4$ & $2201(16.5,15.8-17.1)$ \\
& $-17.8)$ & \\
Rural & $2685(77.7,76.3-$ & $10231(76.5,75.8-77.3)$ \\
& $79.1)$ & $933(7.0,6.6-7.4)$ \\
Estate & $196(5.7,4.9-6.5)$ & $13365(100.0)$ \\
\hline Total & $3454(100.0)$ & \\
\hline
\end{tabular}

\section{Susceptibility indices}

There were no malaria cases detected among the survey population or among fever patients (Table 5). There were 177 persons who had history of fever within the last 2 weeks, and no one gave a past history of malaria within the last 3 years of the survey.

Table5: Biological susceptibility indices

\begin{tabular}{|c|c|}
\hline \multicolumn{2}{|l|}{ Susceptibility indicators } \\
\hline & $\begin{array}{c}\text { No. }(\%, 95 \% \mathrm{CI}) \\
(\mathrm{N}=13365)\end{array}$ \\
\hline Age under 5 and over 65 & $2,186(16.4,15.7-16.9)$ \\
\hline Male gender & $6,640(49.7,48.8-50.5)$ \\
\hline Pregnant mothers & $126(35.6 *, 33.6-47.7)$ \\
\hline $\begin{array}{l}\text { Parasitaemia status } \\
\text { Slide positive cases among population }\end{array}$ & $0(0.0)$ \\
\hline $\mathrm{RDT}^{* *}$ negative & $6,069(100.0)$ \\
\hline RDT** not done & $7,296(54.6,53.7-55.4)$ \\
\hline Microscopy negative & $12,420(100.0)$ \\
\hline Microscopy not done & $945(7.1,6.4-7.5)$ \\
\hline Slide positive cases among fever patients $(\mathrm{n}=177)$ & $0(0.0)$ \\
\hline Past history of malaria within 3 years & $0(0.0)$ \\
\hline
\end{tabular}

Generic susceptibility indices: Generic susceptibility indices considered were sector of residency, been abroad within last 3 years and wealth quintiles. The proportion of population who had been abroad within the last 3 
years in the urban sector $(4.5 \%, \mathrm{n}=99)$ was significantly higher than that of the rural $(2.8 \%, \mathrm{n}=288)$ and estate sectors $(0.2 \%, n=2)\left(x_{4}{ }^{2}=66.103 ; p<0.001\right)($ Table 6$)$.

Table 6: Distribution of population who had been abroad by sector of residence

\begin{tabular}{|c|c|c|c|c|}
\hline \multirow[t]{2}{*}{ Sector of residence } & \multicolumn{3}{|c|}{ Been abroad within last 3 years } & \multirow[b]{2}{*}{$\begin{array}{c}\text { Total } \\
\text { No. } \\
(\%, 95 \% \text { CI })\end{array}$} \\
\hline & $\begin{array}{c}\text { Yes } \\
\text { No. } \\
(\%, 95 \% \text { CI }) \\
\end{array}$ & $\begin{array}{c}\text { No } \\
\text { No. } \\
(\%, 95 \% \text { CI }) \\
\end{array}$ & $\begin{array}{c}\text { Don't know } \\
\text { No. } \\
(\%, 95 \% \mathrm{CI})\end{array}$ & \\
\hline \multirow{2}{*}{ Urban } & 99 & 2082 & 20 & 2201 \\
\hline & $(4.5,3.7-5.5)$ & $(94.6,93.6-95.5)$ & $(0.9,0.6-1.4)$ & $(16.5,15.8-17.1)$ \\
\hline \multirow[t]{2}{*}{ Rural } & 288 & 9773 & 170 & 10231 \\
\hline & $(2.8,2.5-3.2)$ & $(95.5,95.1-95.9)$ & $(1.7,1.4-1.9)$ & $(76.6,75.8-77.3)$ \\
\hline \multirow[t]{2}{*}{ Estate } & 2 & 931 & $0(0.0)$ & 933 \\
\hline & $(0.2,0.03-0.8)$ & $(99.8,99.2-99.9)$ & & $(69.8,65.5-74.3)$ \\
\hline \multirow[t]{2}{*}{ Total } & 389 & 12786 & 190 & 13365 \\
\hline & $(2.9,2.6-3.2)$ & $(95.7,95.3-96.0)$ & $(1.4,1.2-1.6)$ & $(100.0)$ \\
\hline
\end{tabular}

$\chi_{4}^{2}=66.103 ; \mathrm{p}<0.001$

The proportion of the survey population who had been abroad within the last 3 years declined up to the 4th quintile; there was a slight rise in the 5 th quintile $\left(\chi_{8} 2=60.985, P<0.001\right)$ (Table 7$)$.

Table 7:Association between having travelled abroad and wealth index

\begin{tabular}{|c|c|c|c|c|}
\hline \multirow[t]{2}{*}{ Wealth Quintiles } & \multicolumn{3}{|c|}{ Been abroad within last 3 years } & \multirow[b]{2}{*}{$\begin{array}{c}\text { Total,No. } \\
(\%, 95 \% \text { CI })\end{array}$} \\
\hline & $\begin{array}{c}\text { Yes, No. } \\
(\%, 95 \% \text { CI })\end{array}$ & $\begin{array}{c}\text { No, No. } \\
(\%, 95 \% \text { CI })\end{array}$ & $\begin{array}{c}\text { Don't know, No. } \\
(\%, 95 \% \text { CI })\end{array}$ & \\
\hline 1st Quintile & $\begin{array}{r}109 \\
(4.1,3.7-4.9)\end{array}$ & $\begin{array}{r}2530 \\
(94.5,93.6-95.3)\end{array}$ & $\begin{array}{r}38 \\
(1.4,1.0-1.9)\end{array}$ & $\begin{array}{r}2677 \\
(20.0,19.4-20.7)\end{array}$ \\
\hline 2nd Quintile & $\begin{array}{r}89 \\
(3.3,2.7-4.1)\end{array}$ & $\begin{array}{r}2583 \\
(96.1,95.3-96.8)\end{array}$ & $\begin{array}{r}15 \\
(0.6,0.3-0.9)\end{array}$ & $\begin{array}{l}2687 \\
(20.1,19.4-20.8)\end{array}$ \\
\hline 3rd Quintile & $\begin{array}{r}63 \\
(2.4,1.8-3.0)\end{array}$ & $\begin{array}{r}2559 \\
(96.3,95.5-97.0)\end{array}$ & $\begin{array}{r}35 \\
(1.3,0.9-1.8)\end{array}$ & $\begin{array}{r}2657 \\
(19.9,19.2-20.6)\end{array}$ \\
\hline 4th Quintile & & $\begin{array}{r}2578 \\
(96.5,95.7-97.1)\end{array}$ & $\begin{array}{r}34 \\
(1.3,0.8-1.8)\end{array}$ & $\begin{array}{r}2673 \\
(20.0,19.3-20.7)\end{array}$ \\
\hline 5th Quintile & $\begin{array}{r}67 \\
(2.5,1.9-3.2) \\
\end{array}$ & $\begin{array}{r}2536 \\
(94.9,94.0-95.8) \\
\end{array}$ & $\begin{array}{r}68 \\
(2.6,2.0-3.2) \\
\end{array}$ & $\begin{array}{r}2671 \\
(20.0,19.3-20.7) \\
\end{array}$ \\
\hline Total & $\begin{array}{r}389 \\
(2.9,2.6-3.2) \\
\end{array}$ & $\begin{array}{r}12,786 \\
(95.7,95.3-96.0) \\
\end{array}$ & $\begin{array}{r}190 \\
(1.4,1.2-1.6) \\
\end{array}$ & $\begin{array}{l}13,365 \\
(100.0) \\
\end{array}$ \\
\hline
\end{tabular}

\section{Discussion}


This study is based on an adaptation of the framework developed by Kienberger S and Hagenlocher M [20] for social vulnerability to vector borne diseases in a malaria control setting to the prevention of reestablishment setting in Sri Lanka after malaria-free certification [16]. Biological susceptibility indicators contribute more to malaria vulnerability [16]. In this study, as expected, persons' resident in urban areas and in the first wealth quintile had traveled overseas more than others. There was a decreasing trend in the proportion of persons traveling with increasing wealth quintile except in the lowest quintile which may be due to migration for labour. Not a single person had a malaria infection in the past three years. A previous study done during the pre-elimination phase in two formerly high endemic districts of Kurunegala and Anuradhapura reported that around $1.4 \%$ had a past history of malaria in the preceding 5 years of the survey [27]. A past history of malaria for three years was considered to rule out potential relapses that have been observed in imported cases after many months of their return to the country.

A number of epidemiologic studies support the link between malaria and migration. The prevalence of malaria is higher in communities with higher levels of immigration in the Amazon [28]. The migration of nonimmune populations from Sri Lanka to malaria endemic countries influences the importation of malaria parasites into the country. In the past few years less than 100 imported cases have been reported annually.

Literature suggests that children under 5 , persons more than 65 years and pregnant females are more susceptible to get malaria. The relationship between malaria transmission and age is well documented by Molineaux, Snow et al., and Snow \& Marsh [29-32]. In high transmission settings, the incidence of malaria peaks in early childhood and then declines with increasing age with acquired immunity due to exposure to malaria infections. In moderate transmission settings, the age of peak transmission is a little later than childhood, while in low transmission settings, such as in Sri Lanka in the past, the risk of infection remains same across all ages [29]. However, Muhlberger et al., report that the risks of death and development of severe complications due to falciparum malaria increase with age in European patients who are non-immune to malaria [33]. Among the surveyed population in the present study, $16.4 \%(n=2186)$ of the population was under 5 or over 65 years.

Pregnant females are more prone to get infections as their immunological responses are lower due to the pregnancy $[29,33]$. In this study, the pregnant population comprised 35.6 per $1000(n=126)$ females of child bearing age (15-49 years).

At the outset, age, sex and pregnancy status were considered as important in the prevention of reestablishment phase as it is in a control phase because for re-establishment a susceptible population is required. In a prevention of re-establishment phase, all population groups will be susceptible due to waning of immunity. The results of this study suggest that, in a prevention of re-establishment phase, these indicators may not be useful indicators of susceptibility to malaria. Based on the results, the most important factor for assessing susceptibility to malaria in the prevention of re-establishment phase is migration; recent travel overseas, wealth quintile and sector of residence are good indicators to monitor susceptibility to malaria.

Parasitaemia was considered as an indicator in the prevention of re-establishment phase specific for Sri Lanka due to large numbers of foreign workers in the country, re-settlement of refugees returning from India in the Northern Province and receptivity in certain areas of the country. As most non-migratory populations will

Page $14 / 23$ 
be aparasitaemic in a non-transmission area, it is proposed that testing for malaria only be done among persons who have a history of travel within the last 3 years.

In the control phase, many factors have been associated with social vulnerability to malaria. In the highlands of East Africa, high levels of malaria vulnerability were found in the highlands where the immunity of the population was very low and in regions with lack of access to education and health services [16]. Lower values were found in regions with relatively low poverty, low population pressure and low conflict-density [16]. In Rwanda, the most influential susceptibility indicators were; population change $(r=0.729)$, average number of persons per bedroom ( $r=0.531)$, number of households affected by droughts and famines $(r=0.591)$, area used for irrigation ( $r=0.611)$, bed net ownership $(r=-0.398)$ and poor housing wall materials $(r=0.378)$ [7]. The authors suggested that vulnerability assessments be done by combining environmental and social drivers to achieve an integrated and complete assessment and that spatial assessment be done without considering administrative boundaries.

As Sri Lanka was one of the first tropical countries in the recent past to eliminate malaria, there were no comparable studies to adapt methodological reproducibility in similar settings. Concept development depended heavily on the views of malaria experts in the country, studies done by experts in malaria control settings and disaster vulnerability studies. Other than vector and parasite factors, human factors in the form of social vulnerability are important to prevent re-establishment of malaria as highlighted in the conceptual framework.

This national survey to assess susceptibility to malaria during the prevention of re-establishment phase is the first study attempted in a country certified as malaria-free. The study did not specifically include or give priority for selection of specific migrant groups such as refugees, migrant workers residing in construction sites and factories. Refugee returnees from India in the Northern Province were included in the household survey as they were already re-settled and included in the sampling frame. It would have been better to include data on aspects such as areas of returning refugees, migrant labour and congregations of other high risk groups to assess generic susceptibility. Identifying these high risk populations is a challenge as there are illegal migrant workers in the country. Thus, there is an urgent need to identify migrant populations in the most vulnerable and receptive areas with potential for local transmission of malaria and to target interventions accordingly to prevent re-establishment of malaria in the country. One good example in the past was the asylum seekers residing in the Gampaha district, which was previously not endemic for malaria, where 17 imported malaria cases were reported in 2013; further local transmission was prevented through a high risk group screening programme [8].

The results from this study are important for public health policy and decision makers in Sri Lanka. It also highlights the need for widening the scope of traditional malaria control, elimination and prevention of reestablishment programmes to include new aspects such as monitoring migration patterns and special areas where high risk groups such as refugees and migrant foreign labour reside. This is a challenge and may require developing new procedures and task shifting of existing staff during the transition from a control to a prevention of re-establishment phase. This special assessment provided timely evidence to plan and implement the prevention of re-establishment of malaria programme in Sri Lanka; the findings will improve the efficiency, effectiveness and sustainability of PoR interventions through advocacy, social mobilization

Page $15 / 23$ 
and inter-sectoral collaboration to optimize the allocation of limited resources and health infrastructure at national level.

\section{Limitations}

The data collected by the interviewer administered questionnaire in the survey were self-reported by the heads of the household. Microscopy or RDT examination could not be done in some persons as they did not give consent for the procedure.

\section{Conclusions}

Urban residents and upper socioeconomic class persons are more likely to travel overseas and bring the parasite into the country. In addition, migration patterns and areas where known high risk groups reside should be monitored. This will require new procedures to be developed and task shifting of existing staff as the programme transits from a control to a prevention of re-establishment phase.

None of the persons in the surveyed population had a malaria infection within the 3 years prior to the survey. As susceptibility to malaria is a dynamic phenomenon, susceptibility to malaria should be assessed every 3-5 years. As baseline data is now available, the Regional Malaria Officers can update the required information. Susceptibility assessments should combine with resilience and receptivity to assess social vulnerability and risk of malaria during prevention of re-establishment of malaria.

\section{Abbreviations}

A/L: Advanced level

AMC: Anti Malaria Campaign

DHS: Demographic Health Survey

GCE: General Certificate of Education

GPS: Global Positioning System

IOM: International Organization for Migration

$\mathrm{MOH}$ : Medical Officer of Health

MOVE:Methods for the Improvement of Vulnerability Assessment in Europe

O/L: Ordinary Level

PCA: Principal components analysis

PHI: Public Health Inspector 
PCR: Polymerase Chain reaction

PHM:Public Health Midwife

PHLT: Public Health Laboratory Technologist

PoR: Prevention of Re-establishment

RDT: Rapid Diagnostic test

SES: socio economic status

SLR: Sri Lanka Rupees

SPSS: Statistical Package for Social Sciences

UN: United Nations

WMR: World Malaria Report

WHO: world health Organization

\section{Declarations}

\section{Acknowledgements}

The authors wish to acknowledge the Director and all regional and central staff of Anti Malaria Campaign, Sri Lanka for the support given during data collection.

\section{Authors' contributions}

$\mathrm{JH}$ was responsible for the concept, design, acquisition of data, analysis,interpretation of data and writing the manuscript under the supervision of RW.

RW contributed to intellectual input and critically revised the paper.

\section{Funding}

Funding for the study was provided by the Anti Malaria Campaign, Ministry of Health through a GFATM grant.

\section{Availability of data and materials}

All data generated or analyzed during this study are available on request.

\section{Ethical approval and consent to participation}

Ethical clearance was obtained from the Faculty of Medicine, University of Colombo. During the survey, the objectives of the study were explained to heads of households and confidentiality assured. Participants were 
explained regarding blood screening for malaria and its importance, using a written participant information sheet. Written consent for voluntary participation was obtained before the data collection.

Permission to conduct the study was obtained from the Provincial Directors of Health Services and Regional Directors of Health Services, local government authorities and Medical Officers of Health.

\section{Consent for publication}

Not applicable

\section{Competing interests}

The authors have declare that they have no competing interests.

\section{Author details}

J Hamsananthy, Acting Consultant Community Physician, Deputy Director General /Laboratory Services Unit, Ministry of Health, Sri Lanka

A R Wickremasinghe, Professor of Public Health, Department of Public Health, Faculty of Medicine, University of Kelaniya

\section{References}

1. WHO. Malaria Fact sheet [Internet]. 2020. Available from: https://www.who.int/news-room/factsheets/detail/malaria

2. Global Malaria Programme: WHO Global. World malaria report 2019 [Internet]. WHO Regional Office for Africa. 2019. Available from:

https://www.who.int/publications/i/item/9789241565721\%0Ahttps://www.who.int/news-room/factsheets/detail/malaria

3. Ministry of Health and Indigenous Medicine Sri Lanka. ANNUAL Health Bullaitin. 2017; Available from: http://www.health.gov.lk/moh_final/english/public/elfinder/files/publications/AHB/2020/AHB_2017.pdf

4. Anti Malaria Campaign. National Malaria Strategic Plan for Elimination and Prevention of Reintroduction - Sri Lanka 2014 - 2018. 2014;1-62.

5. Annual Report 2016. Anti Malaria Campaign. 2016.

6. Assessment of Malariogenic Potentioal to inform Elimination Strategies and Plan to prevent Reestablishments. World Health Organization; 2019.

7. Bizimana J, Twarabamenye E, Kienberger S. Assessing the social vulnerability to malaria in Rwanda. 2015;14(1):1-21.

8. Dharmawardena P, Premaratne RG, De Aw Gunasekera WKT, Hewawitarane M, Mendis K, Fernando D. Characterization of imported malaria, the largest threat to sustained malaria elimination from Sri Lanka. Malar J. 2015;14(1). 
9. Anti Malaria Campaign. Case management [Internet]. Anti Malaria Campaign. 2018. Available from: http://www.malariacampaign.gov.Ik/index.php/en/resources/statistics/case-management

10. Wiwanitkit V. Co-infection between tuberculosis and malaria: A consideration on interaction of molecules and pathogenesis. J Vector Borne Dis. 2006;43(4):195-7.

11. Fernando P. Past malaria epidemics in Sri Lanka - an analysis. J Coll Community Physicians Sri Lanka [Internet]. 2014;19(1):27-41. Available from: http://www.sljol.info/index.php/JCCPSL/article/view/7624

12. Vivek, H. Kristian Heggenhougen VHP. The behavioural and social aspects of malaria and its control.

13. Weeresinghe S. The Influence of Social Factors towards Resurgent Malaria and its Mitigation Using Sri Lanka as a Case-study. Procedia Econ Financ [Internet]. 2014;18(June):802-6. Available from: http://linkinghub.elsevier.com/retrieve/pii/S2212567114010053

14. Kirkbya K, Galappaththy GNL, Kurinczuk JJ, Rajapakse S, Deepika Fernando S. Knowledge, attitudes and practices relevant to malaria elimination amongst resettled populations in a post-conflict district of northern Sri Lanka. Trans R Soc Trop Med Hyg. 2013;107(2):110-8.

15. Department of Census and Statistics. Sri Lanka Demographic and Health Survey 2016 Key Findings. 2016;1-24. Available from: http://www.statistics.gov.Ik/social/DHS_2016a/DHS_presentations/Key Findings.pdf

16. Sri Lanka Department of Census and Statistics. Sri Lanka Demographic and Health Survey 2006-07. 2009;(May):201. Available from: http://www.statistics.gov.lk/social/DHS 200607 FinalReport.pdf

17. Cutter SL, Boruff BJ, Shirley WL. Social vulnerability to environmental hazards. Soc Sci Q. 2003;84(2):242-61.

18. Turner BL, Kasperson RE, Matson PA, McCarthy JJ, Corell RW, Christensen L, et al. A framework for vulnerability analysis in sustainability science. Proc Natl Acad Sci U S A. 2003;100(14):8074-9.

19. Wisner B, Blaikie P, Cannon T, Davis I. At risk: natural hazards, peoples vulnerability and disasters. Risk Nat Hazards Peoples Vulnerability Disasters. 2014;1-471.

20. Kienberger S, Hagenlocher M. Spatial-explicit modeling of social vulnerability to malaria in East Africa. 2014;1-16.

21. Implications of Spatial Scales and Reporting Units for the Spatial Modelling of Vulnerability to Vectorborne Diseases. 2015;197-206.

22. Shea Oscae Rustein KJ. The DHS Weath Index. In: Journal of Visual Languages \& Computing [Internet]. 2559. p. 55. Available from: https://www.m-

culture.go.th/mculture_th/download/king9/Glossary_about_HM_King_Bhumibol_Adulyadej's_Funeral.pdf

23. Central Bank of Sri Lanka. Economic and Social Statistics of Sri Lanka 2015.

24. Lwanga S., Lemeshow S. Table Minimum Sample Size in Health Studies. Sample Size Determination in Health Studies. A Practical Manual. 1991. p. 1-58.

25. WHO. Malaria indicator survey: basic documentation for survey design and implementation / Roll Back Malaria Monitoring and Evaluation Reference Group. 2005;(July).

26. Belize SI of. Mid-Year Population Estimates by Age Group and Sex. 2009;2020:300. Available from: http://www.statisticsbelize.org.bz/dms20uc/dynamicdata/docs/20090511184813_2.pdf 
27. Rajakaruna RS, Alifrangis $\mathrm{M}$, Amerasinghe $\mathrm{PH}$, Konradsen F. Pre-elimination stage of malaria in Sri Lanka: Assessing the level of hidden parasites in the population. Malar J. 2010;9(1):1-6.

28. International organization for Migration, World Health Organization. Population mobility and malaria. 2017. $106 \mathrm{p}$.

29. Kleinschmidt I, Sharp B. Patterns in age-specific malaria incidence in a population exposed to low levels of malaria transmission intensity. Trop Med Int Heal. 2001;6(12):986-91.

30. Molineaux L. The epidemiology of human malaria as an explanation of its distribution, including some implications for its control. In: Malaria: Principles and Practice of Malariology, Vol. 2 (eds WH Wernsdorfer \& I McGregor). Churchill Livingstone, London, 1998 pp. 954-955.

31. Snow RW, Omumbo JA, Lowe Bet.al. Relation between severe malaria morbidity in children and level of Plasmodium falciparum transmission in Africa. Lancet 1997 349, 1650- 1654.

32. Snow RW\& Marsh K (1998a) New insights into the epidemiology of malaria relevant for disease control. British Medical Bulletin 54, 293- 309.

33. Muhlberger N, Jelinek T, Behrens RH, Gjorup I, Coulaud JP, Clerinx J, et al. Age as a Risk Factor for Severe Manifestations and Fatal Outcome of Falciparum Malaria in European Patients: Observations from TropNetEurop and SIMPID Surveillance Data. Clin Infect Dis [Internet]. 2003;36(8):990-5. Available from: https://academic.oup.com/cid/article-lookup/doi/10.1086/374224

\section{Figures}

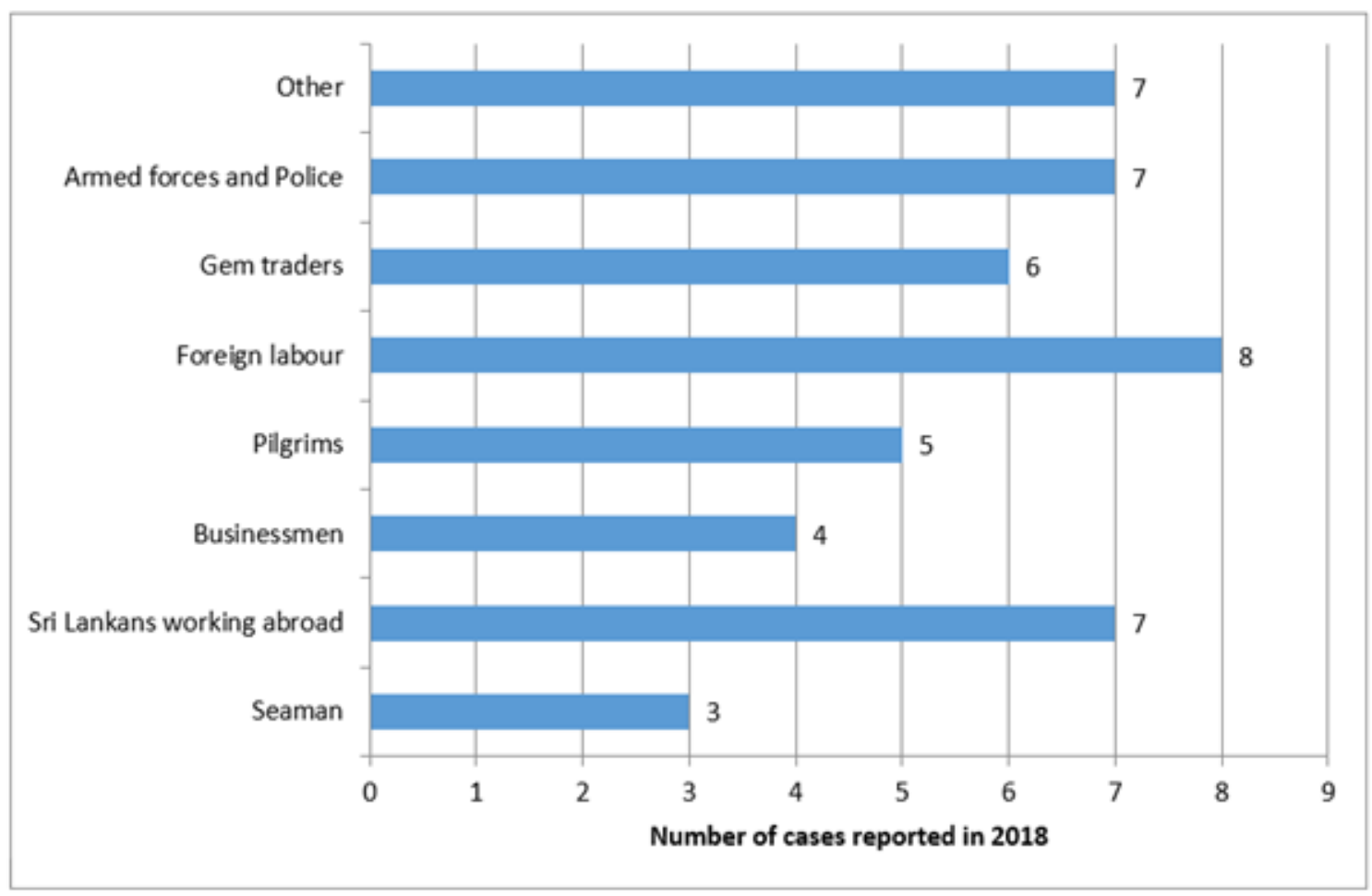

Figure 1 
Malaria cases reported in Sri Lanka in 2018 by risk category [9]

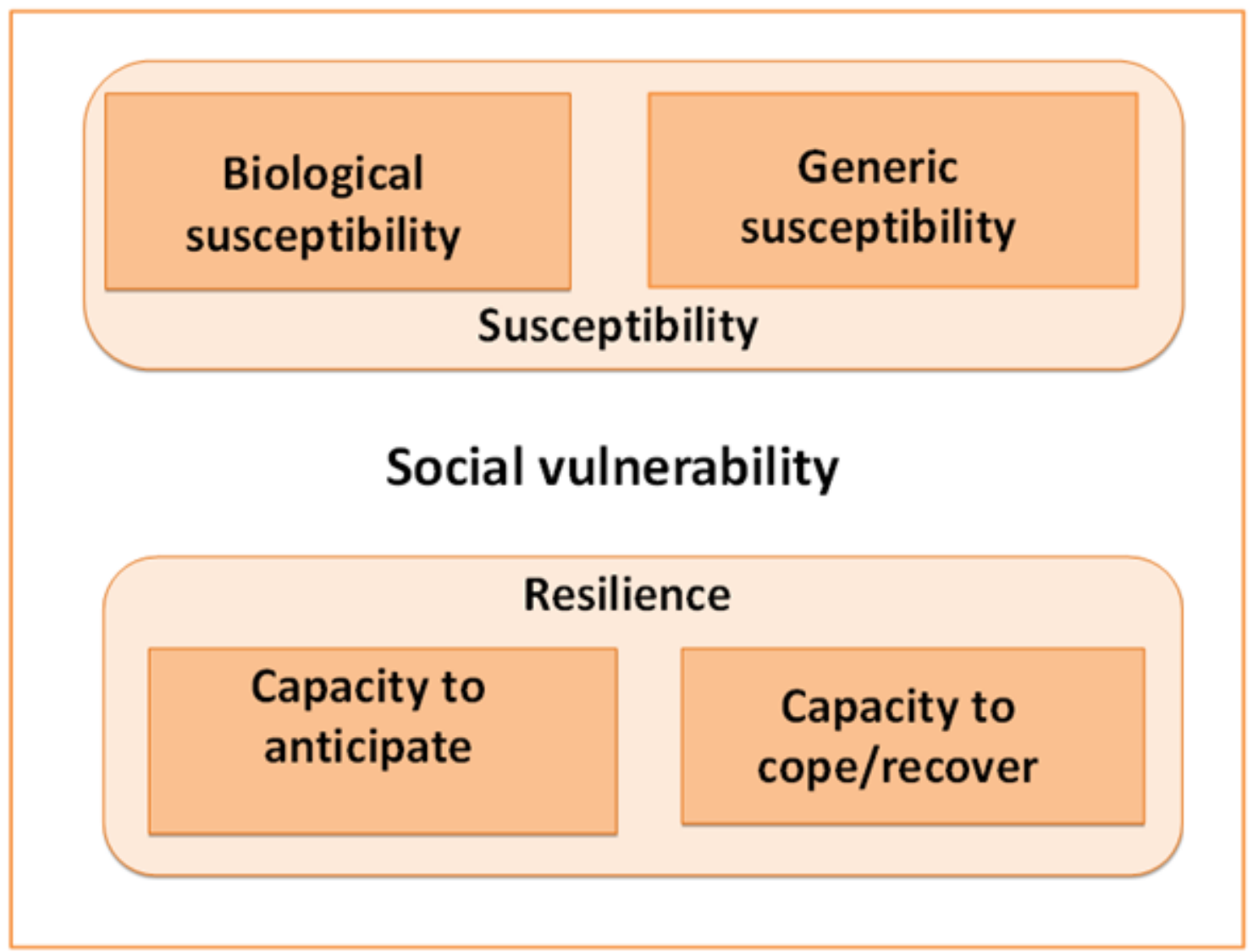

Figure 2

Conceptual framework for social vulnerability adapted from Kienberger, S., \& Hagenlocher, M. [20] 


\begin{tabular}{|l|l|}
\hline \multicolumn{1}{|c|}{$\begin{array}{c}\text { Susceptibility to } \\
\text { Malaria }\end{array}$} \\
\begin{tabular}{|l|l|}
\hline Biological susceptibility \\
1.Age - Sex
\end{tabular} \\
$\begin{array}{l}\text { 2.Pregnancy } \\
\text { 3.Prevalence of parasitaemia } \\
\text { 4.Immunity to malaria-past } \\
\text { 2.Residency of the } \\
\text { population } \\
\text { (Urban/rural/Estate) }\end{array}$ \\
\hline
\end{tabular}

Figure 3

Adapted framework for susceptibility to malaria during the prevention of re-establishment phase from Kienberger and Hagenlocher [20] 


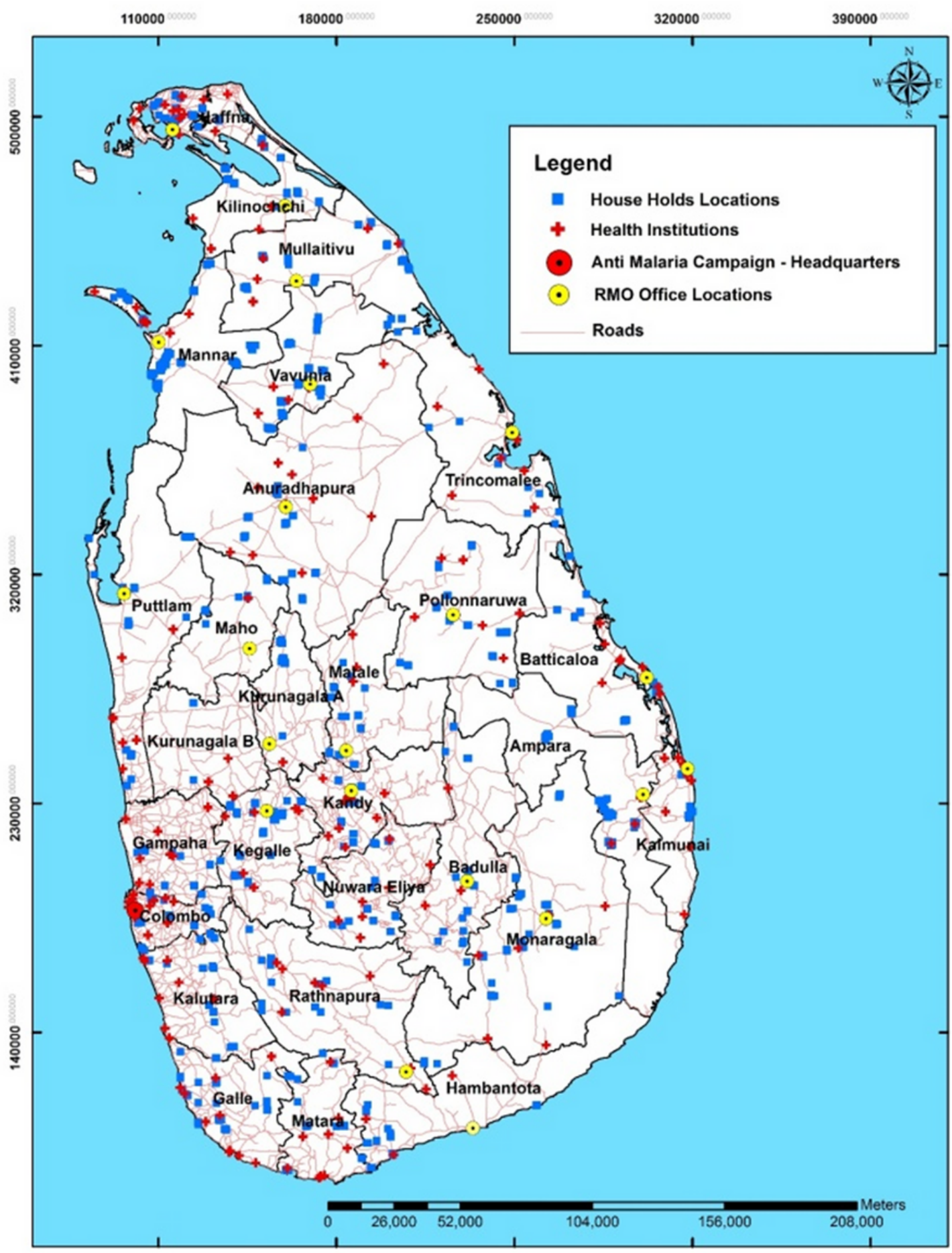

Figure 4

Geographic distribution of surveyed households 